\title{
XLII. On fluorine in recent and fossil bones, and the sources from whence it is derived
}

\section{J. Middleton Esq.}

To cite this article: J. Middleton Esq. (1844) XLII. On fluorine in recent and fossil bones, and the sources from whence it is derived, Philosophical Magazine Series 3, 25:166, 260-262, DOI: $10.1080 / 14786444408644987$

To link to this article: http://dx.doi.org/10.1080/14786444408644987

曲 Published online: 30 Apr 2009.

Submit your article to this journal $\sqsubset$

Џll Article views: 2

Q View related articles $\square$ 
phuric acid at intervals of about a second, the spot $b$ is heated to redness by means of a spirit-lamp. When this point is at. tained, another strong spirit flame is applied to the mixture progressing from $a$ to $f$, until all arsenic is expelled (the first flame continues at the same time acting at $b$ ): the reduced arsenic precipitates at the spot $c$ forming a mirror, whilst an exceedingly small portion escapes at $d$ and fills the air with the smell of garlic. The second spirit-lamp is at last slowly advanced to the spot $b$, so as to drive towards $c$ all the arsenic which has adhered to the walls of the wide tube. After this, both lamps are removed, the tube closed at the point $d$ by fusion, and heat applied progressively from the point $d$ towards $c$, so as to contract the mirror on this side also, which causes it to exhibit a particularly fine and metallic appearance; the tube is then cut off at the point $f$, closed, sealed, and thus becomes a permanent evidence, which may be referred to in any future point of the legal proceedings. The remaining two-thirds of the sulphuret of arsenic (vide supra) are also put into a small glass tube, and this too is then closed and sealed and preserved for reference.

If sulphuret of zinc or sulphuret of antimony be present, together with the sulphuret of arsenic, the zinc and the antimony will be obtained in their metallic state upon dissolving in water the residue found in the reduction-tube (antimony is also found in the solution); they must be deternined by the ordinary methods now in use. Their weight is calculated upon the whole amount of the residue originally contained in the small porcelain basin (vide D), and the weight of their corresponding sulphates subtracted from the total weight of the residue. The remainder is the amount of sulphuret of arsenic corresponding to the arsenic present.

XLII. On Fluorine in Recent and Fossil Bones, and the sources from rohence it is derived. By J. MiddeEton, Esq.*

HAVING been for some time past engaged in investigations, not yet matured, on the absolute and relative quantities of fluorine in fossil bones, I was readily led to inquire into its presence, or otherwise, in recent bones. The high authority of Berzelius had indeed satisfied me on this subject, and I might not have felt a motive to examination for myself had I not lately heard the fact doubted and disputed before the Chemical Society and elsewhere with an earnestness which could only proceed from conviction. The readiness

* Communicated by the Chemical Society; having been rend May 6, 1844 : on the subject of this paper, see the author's previous one, p. 14, and also Dr. Daubeny's, p. 122 of the present volume. 
with which the authorities of the University College acceded to my request for materials, as well for this as for my more laborious investigations, left me no difficulty, and deserves my best acknowledgements.

I easily obtained conclusive evidence of the presence of fluorine in the following portions of the human skeleton, the bones operated upon being from the dissecting-room :-The occiput, the vertebra, the humeriss, the femur, the teeth, the femur of a foetus of $6 \frac{1}{2}$ months.

I examined also the arm, including the scapula, of a foetus of $3 \frac{1}{2}$ months, but could obtain no evidence of the presence of fluorine in it, a result which, considering the small quantity of osseous matter involved, was, perhaps, to have been looked for.

I determined also the presence of fluorine in the entosternal bones of the sternum of a recent tortoise.

Any one who may continue to entertain doubts on this subject, and whose object is the recognition and discovery of truth, may readily convince himself by using the means employed by me. I broke a portion of the bones to be examined into small fragments, and subjected them to the action of con" centrated sulphuric acid in a platinum crucible covered, as is usual in such operations, by a plate of glass endued with an etched coating of wax. I applied the flame of a spirit-lamp from time to time, so moderating the heat as to sustain action of the acid upon the materials without projection upward of the substances against the glass. I prevent the melting of the wax by keeping a muslin rag moist with alcohol upon its upper surface. The time occupied by each experiment was between five and ten minutes.

Through these and other investigations above alluded to, I have ascertained the presence of fluorine in the organic remains of Carnivora, Herbivora, Reptilia, Pisces, as also in the recent bones of men and reptiles. The increase of fluorine in fossil bones is apparently greater in proportion to the remoteness of the period at which they lived, where the character of entombment is similar. These facts, taken conjointly, seemed to me to need for their explanation a more general source of fluorine than has been heretofore $I$ believe supposed. It occurred to me that ordinary water might be the vehicle, and if so, the presence of fluorine in recent bones would not only be accounted for, but also its accumulation in fossil bones, being filtered from the moisture circulating in the earth's crust. In order to ascertain whether facts would be found to sustain this view, I examined the following substances :- 


\section{Dr. Stenhouse on the occurrence of Mannite in the}

First. A deposit, chiefly of sulphate of lime, from, as it appeared, a chloride of calcium vat, and found it to contain fluorine, though in small quantity. As it was suggested to me, however, that glass retorts used for the distillation of hydrochloric acid have been known to be thereby corroded, I did not attach much weight to the result, although I drew encouragement from it.

Second. A deposit formed in a wooden conduit pipe in a coal mine, procured for me by my friend Dr. Falconer, and found it to contain a still greater proportion of fluorine than the former.

Third. A stalactitic deposit, said to have been formed in an aqueduct in France. It was of a pure white colour, and made up of very thin and scaly concentric layers, being at the same time very incompact : it contained no fluorine.

Fourth. A stalactitic deposit from a cave in old red sandstone, furnished to me by Mr. Arrott, to whom for this and for other assistance in my investigations $I$ am much indebted : this $I$ found to contain fluoride of calcium to the extent of about 9 per cent. The stalactite consisted chiefly of carbonate of lime.

Fifth. The crust formed on the inside of a kettle used for the boiling of water: this I found to afford faint but distinct proof of the presence of fluorine.

Lastly. A fragment of a vein of sulphate of barytes found in the sandstone above mentioned. This also contained fluorine, though in much less proportion than the stalactite of the fourth experiment.

The above are the only substances, sufficiently diverse in their origin, which I have had an opportunity of examining, and the facts $I$ have elicited from them seem to confirm the justness of my theory of the prime sources of fluorine in bones. It follows, as a necessary corollary, that it exists in most if not all vegetables, though perhaps in minuteness of quantity, that may enable it often to elude detection.

XLIII. On the occurrence of Mannite in the Laminaria saccharina and other Sea-roeeds. By John Stenhouse, Ph.D.*

MORE than thirty years ago the Laminaria saccharina, with some others of our commonest sea-weeds, were examined by Vauquelin, who detected in several of them a sweet-tasted

* Communicated by the Chemical Society; having been read May 6, 1844. 